\title{
Upregulation of miR-483-3p contributes to endothelial progenitor cells dysfunction in deep vein thrombosis patients via SRF
}

Lingshang Kong ${ }^{1 \dagger}$, Nan $\mathrm{Hu}^{1+}$, Xiaolong Du ${ }^{1}$, Wenbin Wang ${ }^{2}$, Hong Chen ${ }^{1}$, Wendong $\mathrm{Li}^{1}$, Sen Wei ${ }^{1}$, Hao Zhuang ${ }^{1}$, Xiaoqiang Li ${ }^{*}$ and Chenglong Li ${ }^{*}$

\begin{abstract}
Background: Endothelial progenitor cells (EPCS) contribute to recanalization of deep vein thrombosis (DVT). This study aimed to detect miRNA expression profiles in EPCs from patients with DVT and characterize the role of miRNA in EPCs dysfunction.

Methods: EPCS was isolated from DVT patients and control subjects, and miRNA expression profiles were compared to screen differential miRNAs. The candidate miRNAs were confirmed by RT-PCR analysis. The targets of miRNA were identified by bioinformatics analyses, luciferase reporter assay and gene expression analyses. The apoptosis, migration and tube formation of EPCs were examined by flow cytometry, transwell assay and matrigel tube formation assay. A rat model of venous thrombosis was established as in vivo model.

Results: We identified miR-483-3p as a candidate miRNA upregulated in EPCs from DVT patients. By using miR483-3p agomir and antagomir, we demonstrated that miR-483-3p decreased the migration and tube formation while increased the apoptosis of EPCS. Moreover, we identified serum response factor (SRF) as the target of miR-483-3p, and showed that SRF knockdown decreased the migration and tube formation while increased the apoptosis of EPCs. In addition, miR-483-3p inhibition led to enhanced ability of homing and thrombus resolution of EPCs in rat model of venous thrombosis.

Conclusions: miR-483-3p is upregulated in EPCs from DVT patients, and it targets SRF to decrease EPCs migration and tube formation and increase apoptosis in vitro, while decrease EPCs homing and thrombus resolution in vivo. MiR-483-3p is a potential therapeutic target in DVT treatment.
\end{abstract}

Keywords: MiR-483-3p, Endothelial progenitor cells, Deep vein thrombosis, Serum response factor, Digital subtract angiography

\section{Background}

Deep vein thrombosis (DVT) occurs when a blood clot forms in the deep vein of human body, and is a common peripheral vascular disease that causes major morbidity and mortality in various medical conditions [1]. Moreover, lower and upper extremities DVT cause

\footnotetext{
*Correspondence: 563677272@qq.com; ning2005@139.com

${ }^{\dagger}$ Lingshang Kong and Nan Hu contributed equally to this work

1 Department of Vascular Surgery, The Second Affiliated Hospital

of Soochow University, No.1055, Sanxiang Rd, Suzhou 215000, Jiangsu,

China

Full list of author information is available at the end of the article
}

post-thrombotic syndrome (PTS) and pulmonary embolism (PE), which could result in over $15 \%$ death rate in the first 3 month after diagnosis [2]. Currently, anticoagulation therapy is the standard method for DVT, but the failure to the removal of existing thrombus and the risk of PE hinder the use of the therapy [3]. Therefore, it is urgent to develop a safe and efficient therapy for DVT treatment.

Endothelial progenitor cells (EPCs), a bone marrow-derived circulating progenitor for the endothelial lineage, play an important role in pathological and physiological neovascularization in the adult $[4,5]$. EPCs were 
recruited into the thrombus during a resolution and involved in thrombus recanalization [6-8]. Lower numbers of EPCs in the thrombus may result in diminished thrombus recanalization and resolution. Therefore, effective recruitment of EPCs into the thrombus may be a problem of clinical significance.

MiRNAs participate in various biological events $[9,10]$, and recent studies suggested that miRNAs are involved in EPCs function [11]. The upregulation of miR-107 in hypoxia condition led to EPCs differentiation inhibition by targeting HIF-1 $\beta$ [12]. miR-130a was involved in the regulation of autophagy function in EPCs via targeting Runx3 [13]. In addition, our previous studies showed that miR-150 and miR-126 contributed to EPCs function in vitro and improved thrombus recanalization and resolution in vivo [14, 15].

Here we reported the upregulation of miR-483-3p in DVT patients and demonstrated that ectopic expression of miR-483-3p attenuated the migration, tube formation and increased the apoptosis of EPCs via SRF in vitro. Moreover, we tested the efficacy of miR-483-3p modified EPCs in the treatment of vein thrombosis using a rat model.

\section{Methods}

\section{Subjects}

Eighty milliliter of peripheral blood were collected from DVT patients $(\mathrm{n}=3)$ and control subjects $(\mathrm{n}=3)$ at the Second Affiliated Hospital of Soochow University, Suzhou, China. The included DVT patients were confirmed by Color doppler ultrasound and lower extremity angiography without a history of hypertension, diabetes mellitus and other chronic diseases. Patients and healthy controls were matched by the age, gender and other risk factors (Table 1). The protocols were approved by the Institutional Review Board of the Second Affiliated Hospital of Soochow University and written informed consent was obtained from each participant.

\section{Isolation of EPCs}

EPCs were isolated and characterized according to previous methods $[16,17]$. Peripheral blood mononuclear

Table 1 Baseline characteristics of DVT patients and healthy controls

\begin{tabular}{lll}
\hline & $\begin{array}{l}\text { Control } \\
(\mathbf{n}=\mathbf{1 3})\end{array}$ & $\begin{array}{l}\text { DVT } \\
(\mathbf{n}=\mathbf{1 3})\end{array}$ \\
\hline Age, years (mean, SD) & $55.4 \pm 11.6$ & $57.1 \pm 13.2$ \\
Gender, females/males & $7 / 6$ & $7 / 6$ \\
Hypertension & 0 & 0 \\
Diabetes mellitus & 0 & 0 \\
Other chronic diseases & 0 & 0 \\
\hline
\end{tabular}

cells (PBMCs) were isolated using Ficoll-Isopaque Plus (Histopaque-1077; Sigma, MO, USA) gradient centrifugation method. The PBMCs were seeded onto fibronectin-coated cell culture flask, cultured in endothelial basal medium-2 (EBM-2; Lonza, MD, USA) supplemented with $20 \%$ fetal bovine serum (FBS), vascular endothelial growth factor (VEGF; R\&D Systems, MN, USA), human recombinant long insulin-like growth factor-1 (R3-IGF), ascorbic acid, and hydrocortisone and maintained at $37{ }^{\circ} \mathrm{C}, 5 \% \mathrm{CO}_{2}$ incubator. Medium change was performed after 4 days culture and early EPCs developed an elongated spindle-shaped morphology after 7 days culture. EPCs were characterized by confocal microscopy and flow cytometry. The cells were incubated with agglutinin 1 (FITC-UEA-1; Sigma Deisenhofen, Germany) and 1, 19-dioctadecyl-3, 3,3939-tetramethylindocar-bocyanine perchlorate (DiI)-labeled acetylated low density lipoprotein (Dil-Ac-LDL) as described previously [18]. Incorporation of DiI-Ac-LDL and binding of FITCUEA-1 were detected under confocal microscope (Leica Microsystems $\mathrm{GmbH}$, Germany). Cells with double positive staining of DiI-Ac-LDL and UEA-1 were identified as EPCs. The phenotypes of EPCs were analyzed for surface expression of CD34, CD133 and VEGFR-2 (all antibodies were purchased from MiltenyiBiotec, Bergisch, Germany). The third or fourth passages of EPCs were used.

\section{MiRNA expression profiles}

Total RNA was extracted from EPCs using Trizol reagent (Invitrogen, CA, USA) according to the manufacturer's instructions. MiRNA expression profiling was performed using a miRNA microarray analysis and miRNA array probes (LC Sciences) according to previous methods [19, 20]. For each sample, triplicates were analyzed and significant differences between DVT and healthy controls for a given detectable miRNA signal were calculated. The ratio of the two sets of detected signals ( $\log 2$ transformed, balanced) and the P values for the t-test were calculated. The differentially detected signals with $\mathrm{P}<0.01$ were analyzed (Table 2).

\section{MiRNA quantitative real time RT-PCR analysis}

Quantitative real time PCR was carried out using a Roche Light Cycler 480 (Roche, Switzerland), miRNA Qqcr Quantitation Kit (GenePharma, Shanghai, China), and 200 ng total RNA. RNA was transcribed into cDNA Synthesis Kit (Thermo Scientific, MA, USA). Expression of the U6 RNA was assessed as an internal control.

\section{Agomir and antagomir transfection}

To overexpress and knockdown miR-483-3p, agomir and antagomir of miR-483-3p were transfected into EPCs using Lipofectamine 3000 (Invitrogen, CA, USA) 
Table 2 The primers of target sequences

\begin{tabular}{|c|c|c|}
\hline Gene name & Primer usage & Sequence $\left(5^{\prime}-3^{\prime}\right)$ \\
\hline \multirow[t]{3}{*}{ hsa-miR-199a-3p } & RT primer & GTCGTATCCAGTGCGTGTCGTGGAGTCGGCAATTGCACTGGATACGACCTGCCC \\
\hline & Forward primer & GGTGTCACTCCTCTCCTCC \\
\hline & Reverse primer & CAGTGCGTGTCGTGGA \\
\hline \multirow[t]{3}{*}{ hsa-let-7e-5p } & RT primer & GTCGTATCCAGTGCGTGTCGTGGAGTCGGCAATTGCACTGGATACGACAACTAT \\
\hline & Forward primer & GGGGTGAGGTAGGAGGTTGT \\
\hline & Reverse primer & GTGCGTGTCGTGGAGTCG \\
\hline \multirow[t]{3}{*}{ hsa-miR-483-3p } & RT primer & GTCGTATCCAGTGCGTGTCGTGGAGTCGGCAATTGCACTGGATACGACAAGACG \\
\hline & Forward primer & GGTGTCACTCCTCTCCTCC \\
\hline & Reverse primer & CAGTGCGTGTCGTGGA \\
\hline \multirow[t]{3}{*}{ U6 (human) } & RT primer & CGCTTCACGAATTTGCGTGTCAT \\
\hline & Forward primer & GCTTCGGCAGCACATATACTAAAAT \\
\hline & Reverse primer & CGCTTCACGAATTTGCGTGTCAT \\
\hline \multirow[t]{3}{*}{ hsa-miR-199a-3p } & Agomir: sense & ACAGUAGUCUGCACAUUGGUUA \\
\hline & Agomir: antisense & ACCAAUGUGCAGACUACUGUUU \\
\hline & Antagomir: sense & UAACCAAUGUGCAGACUACUGU \\
\hline \multirow[t]{3}{*}{ hsa-let-7e-5p } & Agomir: sense & UGAGGUAGGAGGUUGUAUAGUU \\
\hline & Agomir: antisense & CUAUACAACCUCCUACCUCAUU \\
\hline & Antagomir: sense & AACUAUACAACCUCCUACCUCA \\
\hline \multirow[t]{3}{*}{ hsa-miR-483-3p } & Agomir: sense & UCACUCCUCUCCUCCCGUCUU \\
\hline & Agomir: antisense & GACGGGAGGAGAGGAGUGAUU \\
\hline & Antagomir: sense & AAGACGGGAGGAGAGGAGUGA \\
\hline rno-miR-483-3p & Overexpression & $\begin{array}{l}\text { GGAUCCGCACUCCUCCCCUCCCGUCUUGUCUGAGAAACAAGACGGAAGGAAACGUCA } \\
\text { CUUUUUUGAAUUC }\end{array}$ \\
\hline rno-miR-483-3p sponge & Sponge & $\begin{array}{l}\text { GGAUCCACAAGACGGGCCCGAGGAGUGCGAUACAAGACGGGCCCGAGGAGUGACCGGUAC } \\
\text { AAGACGGGCCCGAGGAGUGUCACACAAGACGGGCCCGAGGAGUGUUUUUUGAAUUC }\end{array}$ \\
\hline \multirow[t]{2}{*}{ rno-miR-483-3p } & Forward primer & GCTGACTCACTCCTCCССTC \\
\hline & Reverse primer & TATGGTTGTTCACGACTCCTTCAC \\
\hline \multirow[t]{2}{*}{ U6 (rat) } & Forward primer & ATTGGAACGATACAGAGAAGATT \\
\hline & Reverse primer & GGAACGCTTCACGAATTTG \\
\hline \multirow[t]{2}{*}{ SRF (human) } & Forward primer & GAGATCGGTATGGTGGTCGG \\
\hline & Reverse primer & GTCAGCGTGGACAGCTCATA \\
\hline \multirow[t]{2}{*}{ SRF siRNA (human) } & Sense & GCAUCAUGAAGAAGGCCUAUU \\
\hline & Anti-sense & UAGGCCUUCUUCAUGAUGCUU \\
\hline \multirow[t]{2}{*}{$\beta$-actin (human) } & Forward primer & ACATCCGCAAAGACCTGTAC \\
\hline & Reverse primer & GCCATGCCAATCTCATCTTG \\
\hline \multirow[t]{2}{*}{ SRF (rat) } & Forward primer & ACCAGCTTCACTCTCATGCC \\
\hline & Reverse primer & TGCATGGGGACTAGGGTACA \\
\hline \multirow[t]{2}{*}{$\beta$-actin (rat) } & Forward primer & ACCCGCGAGTACAACCTTC \\
\hline & Reverse primer & ATGCCGTGTTCAATGGGGTA \\
\hline
\end{tabular}

according to the manufacturer's instructions. Cells were collected at $48 \mathrm{~h}$ after transfection, and the expression of miRNA was confirmed by real time RT-PCR.

\section{Migration assay}

Migration assay was performed in a transwell system as described previously. EPCs $\left(2 \times 10^{5}\right.$ cells $)$ were resuspended in serum-free EBM-2 medium and seeded on the upper chamber. The lower chamber was filled with EBM-2 medium supplemented with $20 \%$ FBS. After incubation at $37{ }^{\circ} \mathrm{C}, 5 \% \mathrm{CO}_{2}$ for $24 \mathrm{~h}$, the cells were stained with hematoxylin and the cell number in each well was counted in three randomly picked fields (200x magnification) under a light microscope. All the experiments were performed in triplicate.

\section{Tube formation assay}

In vitro matrigel tube formation assay was performed to determine the angiogenic activity of EPCs as previously described [18]. Briefly, EPCs $\left(5 \times 10^{4}\right.$ cells $)$ were 
transfected with miR-483-3p agomir or antagomir and then seeded onto matrigel coated 48-well plate, and tubular structures of EPCs in the matrigel were evaluated under microscope after $24 \mathrm{~h}$ incubation. To quantify the length of newly formed tubes, six random phase contrast photos per well were taken, and the length of each tube was measured using Image J software. Tube length obtained from miR-483-3p antagomir transfected cells was set to 100 .

\section{Apoptosis analysis by flow cytometry}

EPCs were stained with annexin $\mathrm{V}$ and propidium iodide (PI) (eBioscience, CA, USA), and analyzed by flow cytometry as previously described [18].

\section{Luciferase assays}

The pMIR-SRF-3' UTR plasmid containing the putative binding site of the SRF $3^{\prime}$ UTR downstream of the firefly luciferase gene was generated by cloning and inserting of a 395 bp sequence located at 3'UTR downstream into the SpeI and HindIII sites of the pMIR-REPORT Luciferase vector (Ambion, TX, USA). For luciferase activity measurement, HEK293 T cells were grown in 24-well plates until 60-70\% confluence and co-transfected with $100 \mathrm{ng}$ Luciferase plasmid and $50 \mathrm{ng}$ Renilla plasmid (Ambion) as a control for transfection efficiency, along with $650 \mathrm{ng}$ miR-483-3p agomir or antagomir or negative control. The activity of Luciferase and Renilla was assessed after $48 \mathrm{~h}$ with the Dual Luciferase Reporter 1000 Assay System (Promega, WI, USA).

\section{Western blot analysis}

EPCs were lysed in RIPA buffer followed by high-speed centrifugation. Cellular proteins were quantified using bicinchoninic acid, separated by sodium dodecyl sulfatepolyacrylamide gel electrophoresis and transferred onto polyvinylidenedifluoride membranes. After blocking, the membranes were incubated with the antibody for serum response factor (SRF) monoclonal (Cell Signaling Technology, MA, USA) or Actin (Sigma, MO, USA). Next the membranes were incubated with horseradish peroxidaseconjugated secondary antibodies and protein bands were detected with SuperSignal West Pico Chemiluminescent Substrate (Pierce, Rockford, IL) on x-ray films (Kodak, Tokyo, Japan).

\section{Lentivirus, vector production and cells transduction}

The lentivirus, vector production and cell transduction were performed as previously described [21-23]. Partial pre-miR-483 sequences flanked by EcoRI and AgeI restriction site were constructed into the $\mathrm{H} 1$ promoter of lentivirus infectious virions pGLV3-H1-GFP-Puro (GenePharma, Shanghai, China). EPCs were infected with the viruses and selected in the presence of $5 \mu \mathrm{g} /$ $\mathrm{ml}$ puromycin (Sigma), and the green fluorescent protein (GFP) signal of the infected cells was detected under microscope, and the expression of the miR-483 cluster in EPCs was measured by quantitative realtime PCR. To generate miR-483-3p sponge lentivirus virion, the sequences to miR-483-3p with mismatches at position 9-12 were constructed into the pGLV3H1-GFP-Puro lentivirus infectious virions and used to infect EPCs.

\section{Rat EPCs isolation}

Male Sprague-Dawley (SD) rats weighted $300 \mathrm{~g}$ were purchased from SLAC Experimental Animal Company (Shanghai, China). Isolation of rat EPCs was performed as previously described $[7,15,24]$. Bone marrow was harvested from both femurs and tibias of SD rats. Density gradient centrifugation with Ficoll-paque (GE Healthcare, Piscataway, NJ, USA) was used to isolate mononuclear cells. The cells were seeded into flask pre-coated with human fibronectin (Sigma) and cultured in EGM2-MV (Lonza, MD, USA) medium at $37{ }^{\circ} \mathrm{C}$ in a $5 \% \mathrm{CO}_{2}$ incubator. After 4 days, non-adherent cells were removed by PBS washing, and the adherent cells were cultured with fresh medium. The third and fourth generations of EPCs were used.

\section{Rat model of venous thrombosis}

The animal protocol was approved by the Institutional Animal Care and Use Committee of Soochow University. SD rats were purchased from the Experiment Animal Center of Soochow University. The rats were anesthetized by intraperitoneal injection of $10 \%$ chloral hydrate. A midline laparotomy was performed. The infrarenal inferior vena cava (IVC) was exposed and all side branches were ligated with 7-0 Prolene suture. The posterior venous branches were blocked by electric coagulation. A 7-0 Prolene suture was tied down on the IVC just below the left renal vein. At the same time, a microvascular clamp was attached to the confluence of iliac veins for 15 min to block the blood flow and induced the thrombus in IVC. The skin was sutured and the rats were allowed to recover after the surgery. Then the rats were divided into four groups for cell transplantion via tail intravenous injection $(\mathrm{n}=10)$ : (A) blank control group (blank control) received same volume of cell culture medium; (B) EPCs/pGLV3-H1-GFP-Puro vector group (EPCs/vector) received $1.0 \times 10^{6} \mathrm{EPCs}$ transfected with pGLV3-H1-GFP-Puro control vector; (C) EPCs/pGLV3H1- GFP-Puro-miR-483-3p group (EPCs/miR- 483-3p) received $1.0 \times 10^{6}$ EPCs transfected with pGLV3-H1GFP-Puro-miR-483-3p; (D) EPCs/pGLV3-H1-GFP-PuromiR-483-3p sponge group (EPCs/miR-483-3p sponge) 
received $1.0 \times 10^{6}$ EPCs transfected with pGLV3-H1GFP-Puro-miR-483-3p sponge.

\section{Histology}

Seven days after the injection of either EPCs or control medium, the animals were sacrificed and IVC segments containing the thrombus were carefully harvested, and excess blood was absorbed with filter paper. The thrombi were weighed and embedded in optimal cutting temperature (OCT) media and flash-frozen in a $-80{ }^{\circ} \mathrm{C}$. Five micrometer cryosections were cut for histological analyses and a confocal microscope (Leica Microsystems) was used to analyze the homing of EPCs. The remaining samples were used for the analysis of thrombus organization and recanalization with hematoxylin and eosin (HE) staining.

\section{DSA}

IVC venography was performed with digital subtract angiography (DSA, GE Innova 3100, USA) by injecting contrast media into rat caudal vein or femoral vein to determine the recanalization and resolution of thrombus in vivo.

\section{Statistical analyses}

All statistical analyses were carried out using SPSS v21 (SPSS, Chicago, IL). Data are presented as mean \pm SEM. Student's t-test or one way ANOVA followed by Least Significant Difference test was used to compare the differences between or among the groups. Univariate comparisons of two independent groups were done using the Mann-Whitney-U test. Comparisons of multiple groups were performed with the Kruskal-Wallis test. $\mathrm{P}<0.05$ was considered significant.

\section{Results}

\section{The upregulation of miR-483-3p in EPCs from patients} with DVT

EPCs were isolated from both DVT patients $(\mathrm{n}=3)$ and healthy donors $(\mathrm{n}=3)$, and the expression of miRNA was determined using a microarray assay (Additional file 1: Figure S1). Three miRNAs (upregulated miR-483 and downregulated let-7e and miR-199a) exhibited significantly fold changes (Fig. 1). To further confirm the accuracy of the microarray data, we performed quantitative RT-PCR to evaluate the expression of miRNA in DVT $(n=3)$ and healthy control $(n=3)$. Our results showed that the expression of miR-483-3p was significantly upregulated (Fig. 1, fivefold increase, $\mathrm{P}<0.05$ ), indicating the potential role of miR-483-3p in DVT.

EPCs colony exhibited a round morphology and formed a central cluster after 3 days of culture (Fig. 2Aa). An elongated spindle-shaped morphology was found in

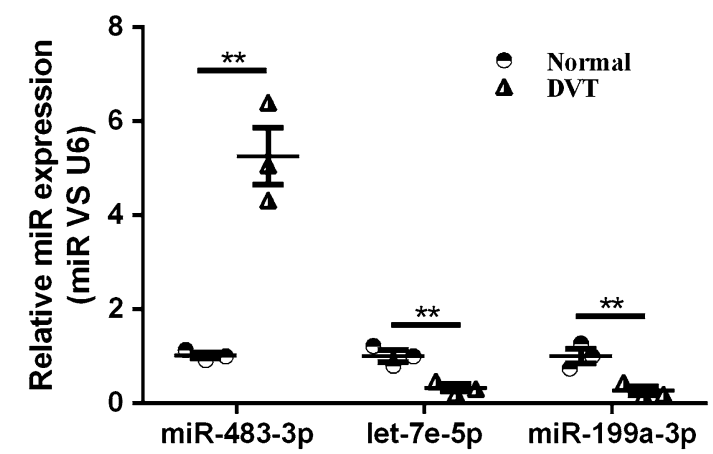

Fig. 1 Differentially expressed miRNAs in EPCs from healthy control and patients with DVT by microarray (Arraystar, human miRNA 18.0 chip). Three aberrantly expressed miRNAs were identified by quantitative real-time PCR. Data are expressed as mean \pm SEM $(n=3$, ${ }^{* *} \mathrm{P}<0.01$ vs. health control)

early EPCs after seventh day of culture (Fig. 2Ab). FACS analysis showed the expression of CD34, CD133 and VEGFR-2 on EPCs at day 14 (Fig. 2B). EPCs were further characterized by double staining with functional marker FITC-UEA-I and Dil-ac-LDL (Fig. 2C).

MiR-483-3p decreased the migration, tube formation and increased the apoptosis of EPCs.

To clarify the role of miR-483-3p in EPCs, we employed miR-483-3p agomir and antagomir to overexpress and inhibit miR-483-3p in EPCs. EPCs transfected with miR483-3p agomir displayed decreased ability of migration (Fig. 3a), tube formation (Fig. 3b) and increased apoptosis (Fig. 3c). EPCs transfected with miR-483-3p antagomir exhibited opposite behaviors on cell migration, tube formation and apoptosis (Fig. 3a-c).

\section{SRF is the target gene of miR-483-3p in EPCs}

Based on multiple databases (TargetScan, Microcosm Targets and RNA22-HAS), SRF was predicted to have a putative miR-483-3p binding sites within its $3^{\prime}$ UTR (Fig. 4a, b).

To confirm that SRF is a direct target of miR-483-3p, we performed luciferase reporter assay and found decreased luciferase activity after a 395 bp region of $3^{\prime}$-UTR SRF was cloned into the luciferase report vector (Fig. 4c, d).

To confirm the ability of miR-483-3p to inhibit SRF expression, we transfected EPCs with miR-483-3p agomir and antagomir. EPCs transfected with miR-483-3p agomir exhibited significantly decreased SRF protein level while EPCs tranfected with miR-483-3p antagomir exhibited increased SRF protein level (Fig. 4e). As expected, we detected reduced protein level of SRF in EPCs after SRF siRNA transfection (Fig. 4f).

In addition, DVT patients $(\mathrm{n}=10)$ and healthy control subjects $(n=10)$ were included to verify the upregulation 


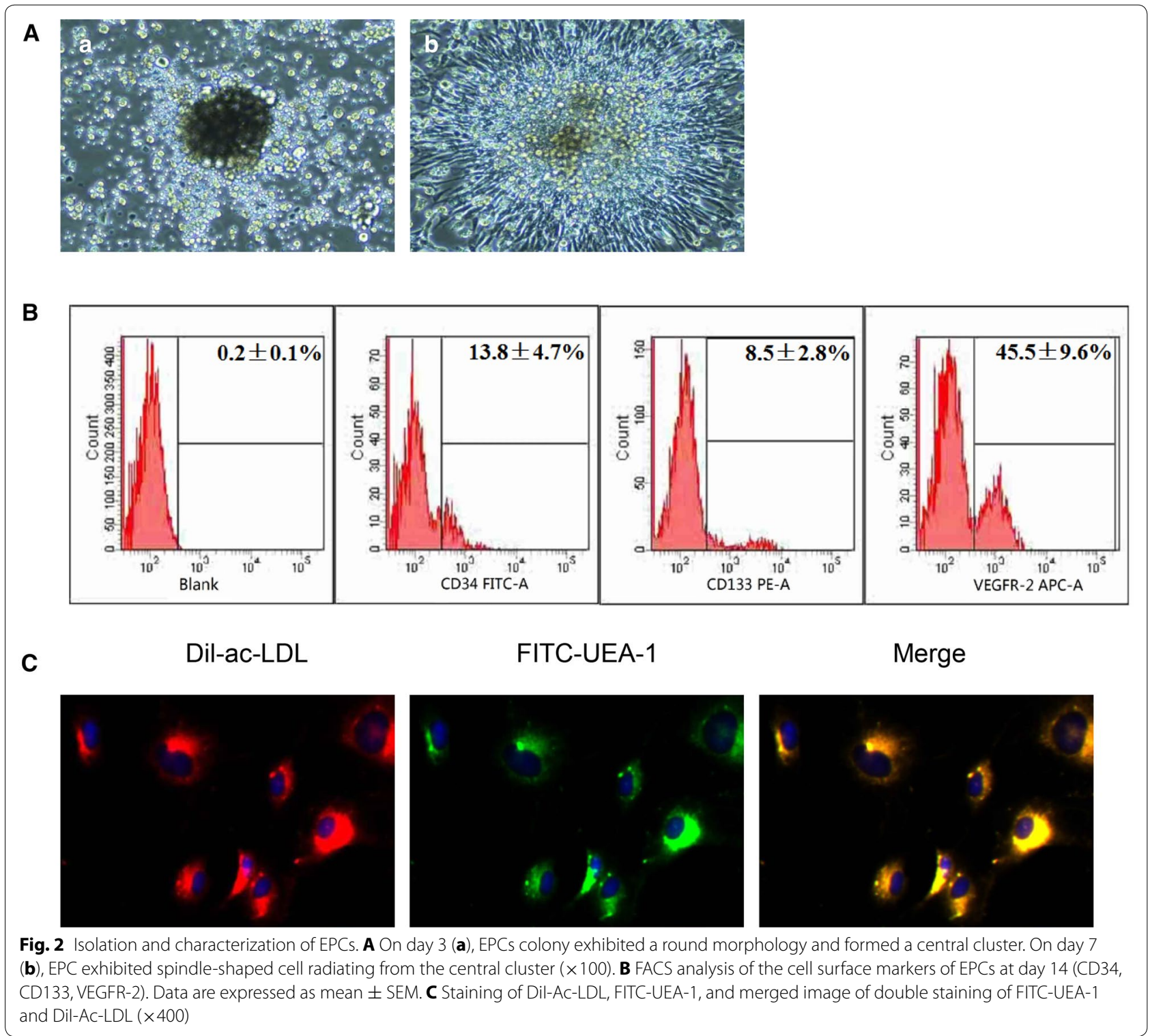

of miR-483-3p in EPCs from DVT patients by quantitative real-time PCR (Fig. 4g). Western blot analysis showed decreased protein level of SRF in DVT patients $(n=10)$ compared to healthy controls $(n=10)$ (Fig. 4h).

\section{MiR-483-3p regulates EPCs function by targeting SRF}

To explore the role of SRF in EPCs function, EPCs were transfected with SRF siRNA. EPCs transfected with SRF siRNA exhibited decreased cell migration (Fig. 5a), tube formation (Fig. 5b) and increased apoptosis (Fig. 5c), compared to EPCs transfected with vehicle controls. To further confirm that miR-483-3p modulated EPCs function by targeting SRF, we performed rescue experiments by co-transfection of miR-483-3p agomir and SRF expression vector in EPCs, and EPCs showed similar trend of cell migration, tube formation and apoptosis as controls (Fig. 5a-c).

\section{Knockdown of miR-483-3P in EPCs via lentivirus-mediated miR-483-3p sponge}

We constructed a miR-483-3p sponge consisted of a decoy vector containing tandem repeated miRNA binding sites downstream of GFP (Fig. 6a). Binding sites for miR-483-3p were complementary in the seed region with a bulge at positions 9-12 to prevent RNA interference-type cleavage and degradation of the sponge RNA constructed into the pGLV3-H1-GFP-Puro lentivirus infectious virions (Fig. 6b). EPCs were infected with 


\section{a}

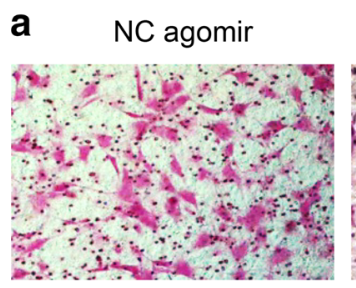

miR-483-3p agomir

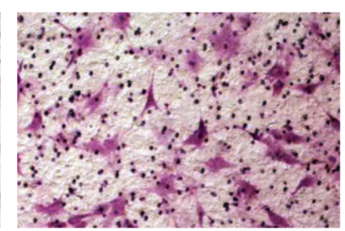

NC antagomir

miR-483-3p antagomir

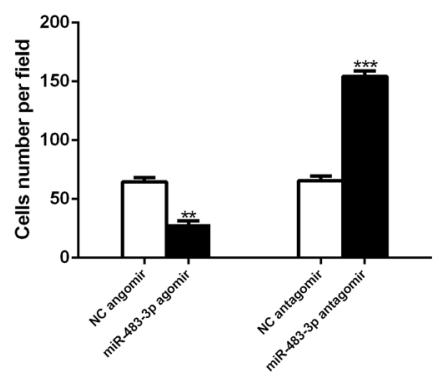

b

NC agomir

miR-483-3p agomir
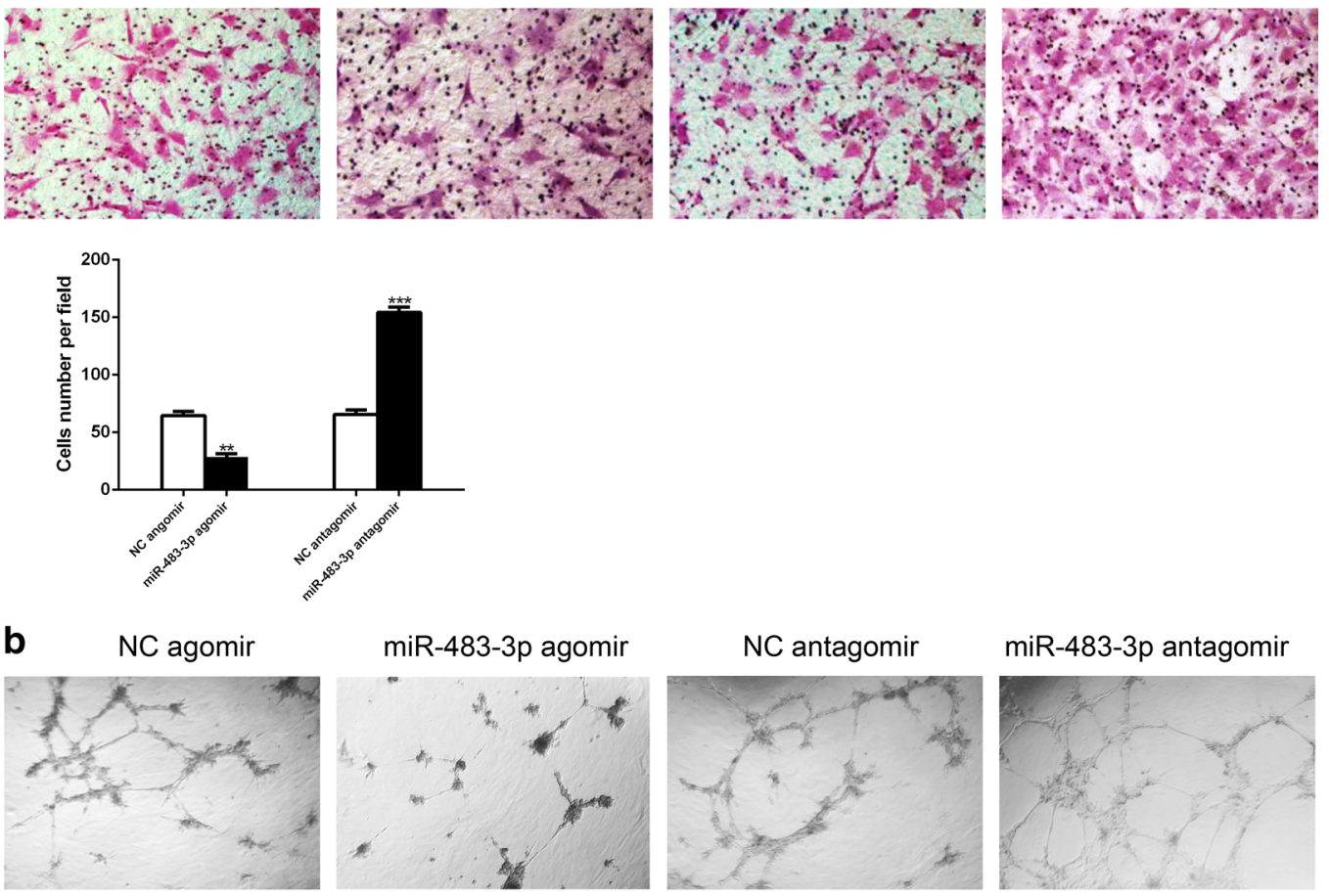

NC antagomir

miR-483-3p antagomir
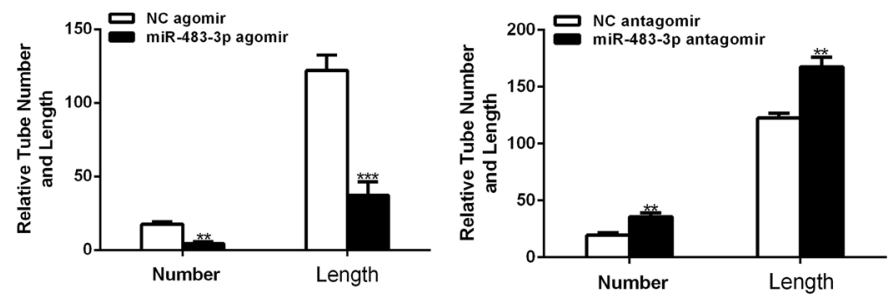

C
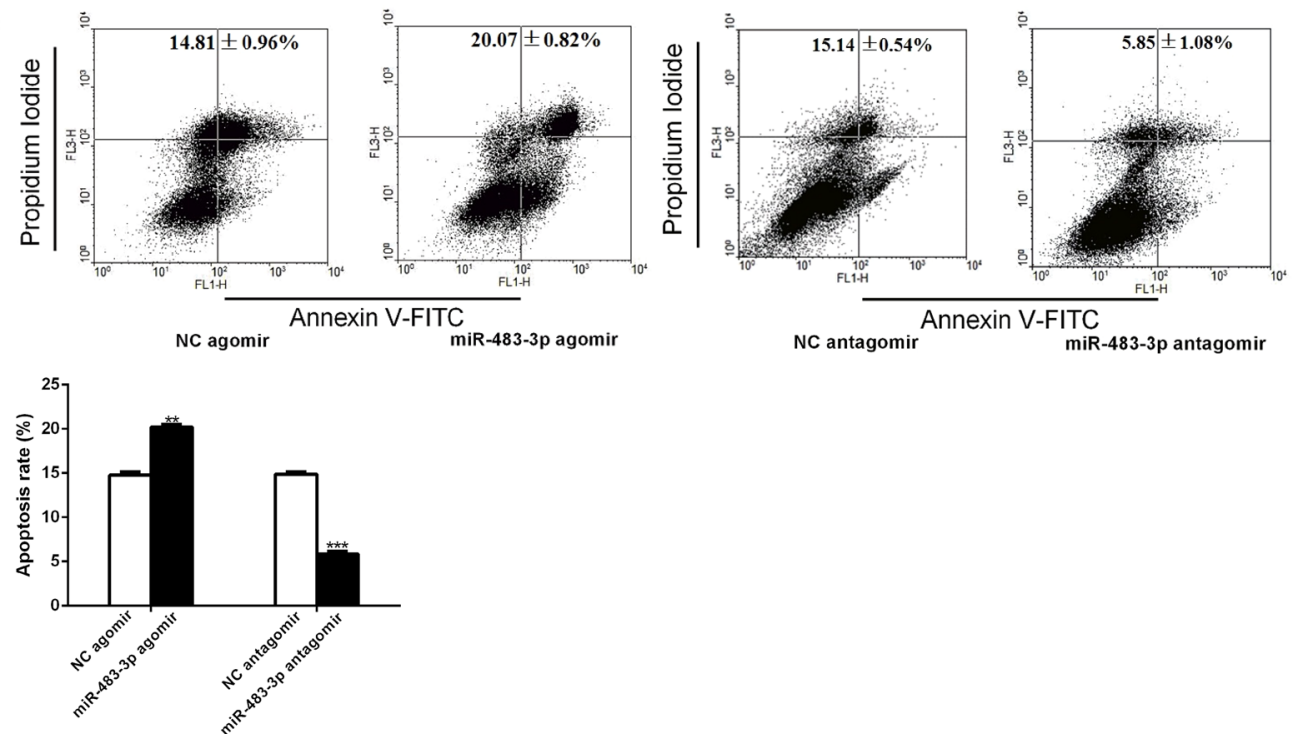

Fig. 3 miR-483-3p regulates migration, tube formation, and apoptosis of EPCs. EPCs were transfected with miR-483-3p agomir or antagomir or negative control. a Migrated cell counting $(\times 200)$. ${ }^{* *} \mathrm{P}<0.01 \mathrm{vs}$. negative control, ${ }^{* * *} \mathrm{P}<0.001 \mathrm{vs}$. negative control $(n=3)$. b Relative tube number and length $(\times 100)$. ${ }^{* *} \mathrm{P}<0.01$ vs. negative control, ${ }^{* * *} \mathrm{P}<0.001$ vs. negative control $(n=3)$. c Cell apoptosis was determined by annexin V/PI staining. ${ }^{* *} P<0.01$ vs. negative control ${ }^{* *} P<0.001$ vs. negative control $(n=3)$. All data are expressed as mean $\pm S E M$ 
a hsa-miR-483-3p 3' UUCUGCCCUCCUCUCCUCACU5'

| ||||||

human SRF-3'UTR $55^{\prime}$... AGCCAGUUCUCCCAGGGAGUGAG3'... 1303-1309

mo-miR-483-3p 3' UGUUCUGCCCUCCCCUCCUCAC5'

| | || || |

rat SRF-3'UTR 5'...AGGGAGGCGGGGAGAAGGAGUGG3'... 114-120

mmu-miR-483-3p 3' UUCUGCCCUCCCCUCCUCACU5'

|| ||||

mouse SRF-3'UTR $5^{\prime}$...GGGCAGCUCUCCCAGGGAGUGAG3'... 1282-1288

b

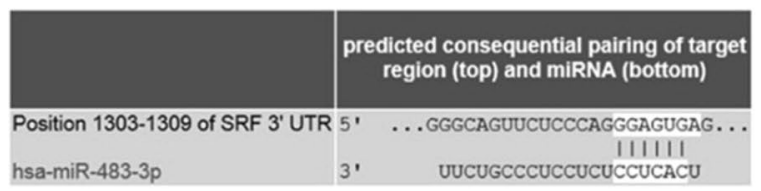

C

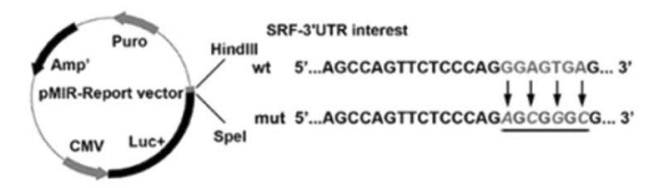

d
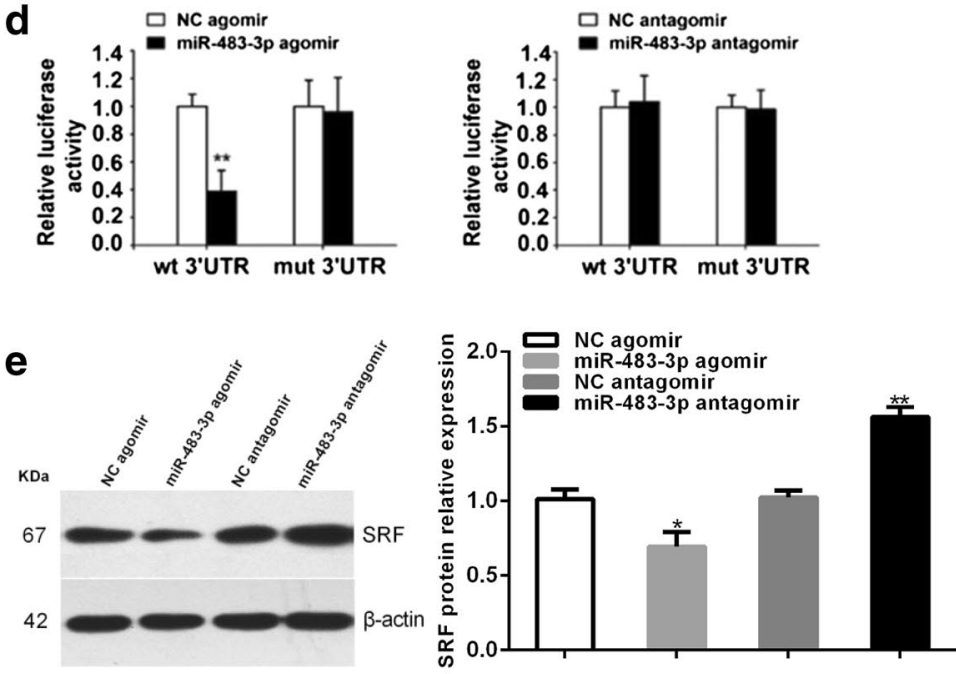

$\mathbf{f}$

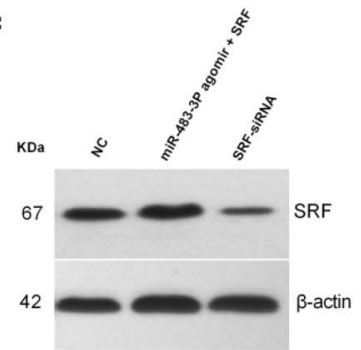

$\mathbf{h}_{\mathrm{kDa}}$ Normal

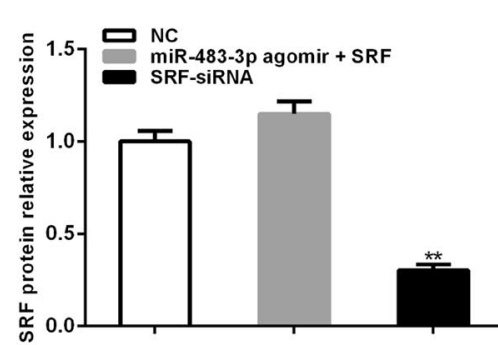

DVT

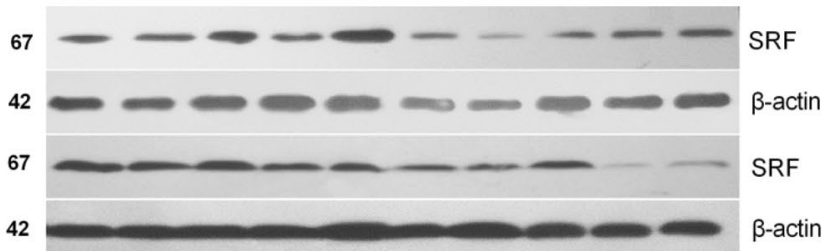

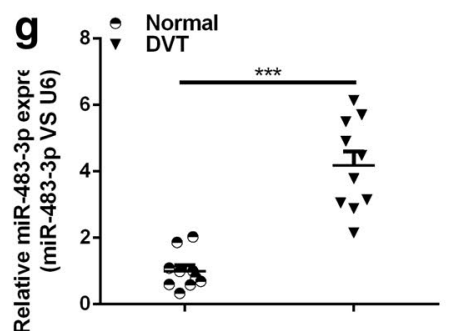

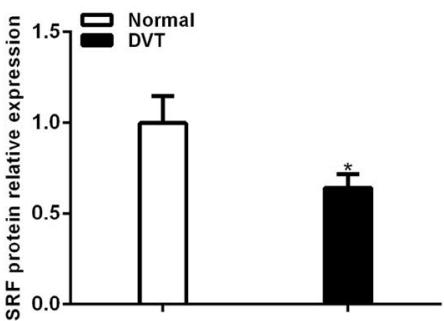


(See figure on previous page.)

Fig. 4 SRF is a validated target of miR-483-3p. a SRF is a putative target of miR-483-3p. Putative binding sites of miR-483-3p in the SRF 3'UTR predicted by TargetScan among different mammalian species. b Putative binding sites of hsa-miR-483-3p in the human SRF 3'UTR (white sequences) predicted by TargetScan. c Schematic graph of the constructed reporter plasmid containing putative binding sites of hsa-miR-483-3p in the SRF $3^{\prime}$ UTR. SRF-3'UTR mut indicates the SRF-3'UTR with mutation in miR-483-3P-binding site. The mutated nucleotides in SRF-3'UTR fragments are underlined. d Dual luciferase report assays were performed on HEK 293 T cells. Each bar represents mean values \pm SEM $(n=3, * * P<0.01)$. e The protein level of SRF in EPC transfected with miR-483-3p agomir and antagomir. Each bar represents mean values $\pm S E M\left(n=3,{ }^{*} P<0.05\right.$ vs. negative control; ${ }^{* *} \mathrm{P}<0.01$ vs. negative control). $\mathbf{f}$ The protein level of SRF in EPC transfected with miR-483-3p agomir and SRF, SRF siRNA. Each bar represents mean values \pm SEM ( $n=3,{ }^{* *} P<0.01$ vs. negative control). $\mathbf{g}$ miR-483-3p expression was measured in healthy control and patients with DVT by quantitative real-time PCR. Data are expressed as mean \pm SEM $\left(n=10,{ }^{* *} P<0.01\right.$ vs. health control). $\mathbf{h}$ The protein level of SRF in patients with DVT and health control. Each bar represents mean values $\pm \operatorname{SEM}\left(n=10,{ }^{*} \mathrm{P}<0.05\right.$ vs. health control)

lentivirus-mediated vector control, miR-483-3p and miR-483-3p sponge, and the expression of the miR-483 cluster was measured by quantitative real-time PCR. MiR-483-3p sponge lentivirus virions totally silenced the expression of miR-483-3p (Fig. 6c). Western blot analysis showed that SRF protein level was significantly increased after miR-483-3p sponge treatment (Fig. 6d).

\section{MiR-483-3p inhibited EPCs homing}

A rat model of DVT was established by inferior vena cava ligation. EPCs transfected with pGLV3-H1-GFP-PuromiR-483-3p were intravenously administrated into the rats. Cyrosections of thrombus were prepared on day 7 after EPCs transplantation. EPCs were found to home and locate around the thrombus after transplantation.

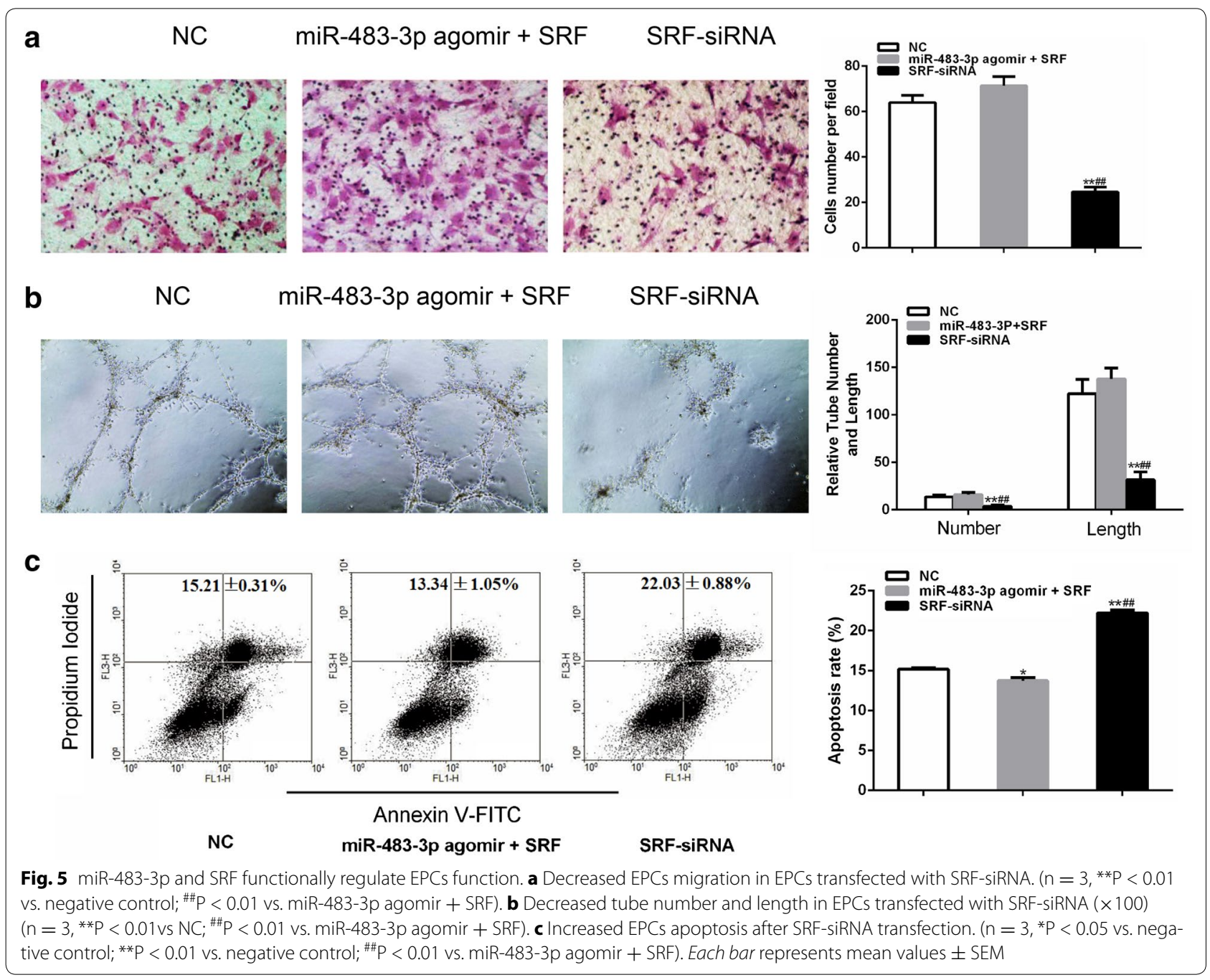




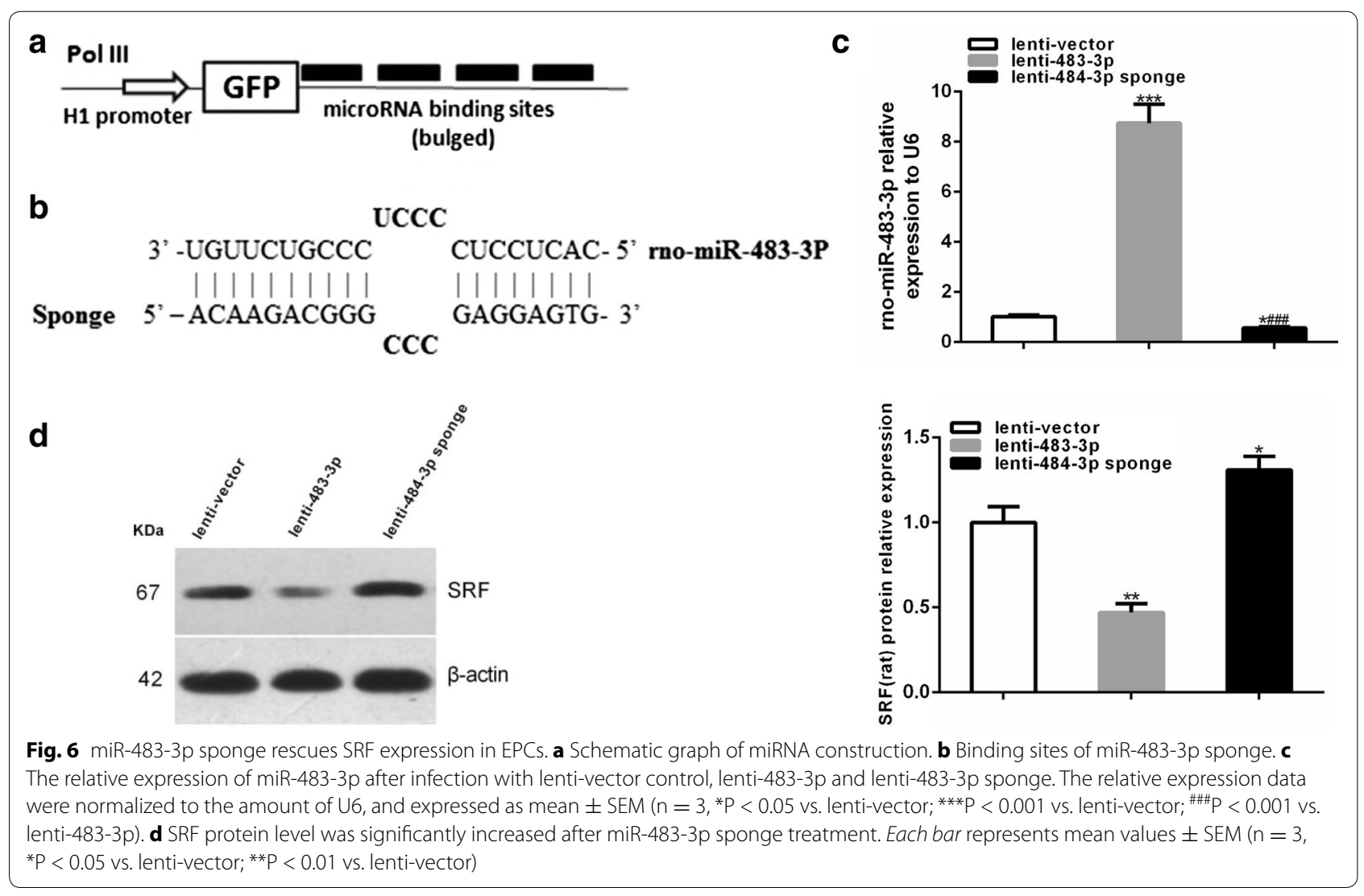

Significantly increased EPCs homing was found in the rats infused with EPCs/miR-483-3p sponge group compared to EPCs/miR-483-3p group on day 7 after EPCs transplantation (Fig. 7a, b).

\section{Inhibition of miR-483-3p promoted thrombus recanalization and resolution}

HE staining showed that nucleated cells, including monocytes, endothelial cells and neutrophil granulocytes entered into the perimeter of the thrombus on day 7 . The red blood cells, platelets and fibrin were dried red in the center of thrombus. There were more nucleated cells and channels in EPCs/vector and EPCs/miR-483-3p sponge group than in control group on day 7 (Fig. 7c). In addition, miR-483-3p sponge decreased the weight of thrombus (IVC + thrombus at harvest). Compared with control group, the weight of thrombus was similar to EPCs/miR-483-3p group, whereas significant decrease of thrombus weight was observed in EPCs/vector and EPCs/miR-483-3p sponge groups on day 7 after transplantation. Furthermore, the thrombus weight of EPCs/miR-483-3p sponge group was even lower than that of EPCs/vector group (18.7 $\pm 6.1 \mathrm{vs.} 30.6 \pm 8.3 \mathrm{mg}$ on day $7, \mathrm{P}<0.05$, Fig. $7 \mathrm{~d}$ ).

DSA has been widely accepted as the reference standard for DVT diagnosis and therefore we evaluated the thrombus recanalization and resolution in vivo by using DSA. A contrast agent was injected into the rats to illustrate the vessel. We observed significantly increased thrombus recanalization and resolution in rats transplanted with miR-483-3p sponge transfected EPCs compared to miR-483-3p transfected EPCs on day 7 (Fig. 7e, f).

\section{Discussion}

In the present study, we reported several important findings on the role of miR-483-3p in EPCs. First, miR483-3p expression was increased in EPCs derived from patients with DVT. Overexpression of miR-483-3p decreased migration and angiogenic potential of EPCs while increased apoptosis of EPCs. Moreover, we identified SRF as the target of miR-483-3p in EPCs. The migration, angiogenic potential and apoptosis of EPCs were positively regulated by SRF, and the suppression of SRF by miR-483-3p contributed to the effects of miR-483-3p on EPCs function. In addition, we established a rat model of vein thrombosis and observed that transplantation with EPCs transfected with miR-483-3p displayed increased homing ability and improved the thrombus recanalization and resolution in vivo. Taken together, our data suggest that miR-483-3p plays an important role in EPCs dysfunction, and upregulated miR-483-3p in EPCs 


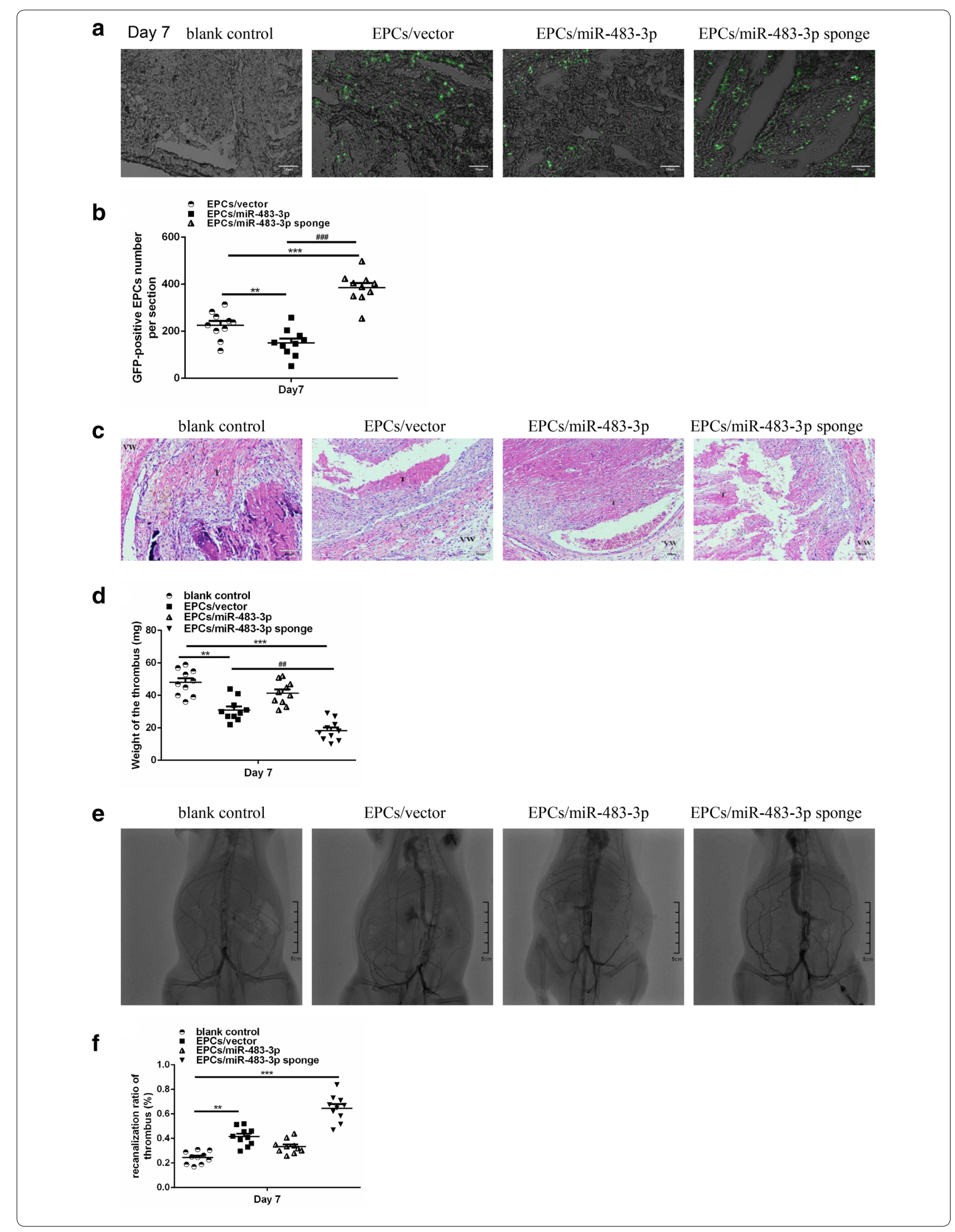


(See figure on previous page.)

Fig. 7 MiR-483-3p decreases EPCs homing, thrombus recanalization and resolution. a Representative images of recruitment of GFP-positive EPCS in the deep venous thrombosis ( $\times 200)$. b Quantification of GFP-positive EPCs in thrombus sections. Data are expressed as mean $\pm S E M(n=10$,

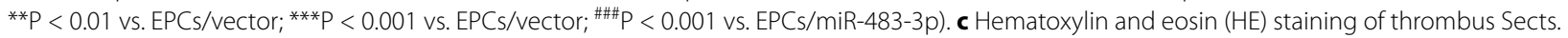
(200x magnification). T means thrombus and VW indicates venous wall. d Weight of the venous thrombi at day 7 post the transplantation. Data are expressed as mean \pm SEM $\left(n=10,{ }^{* *} P<0.01\right.$ vs. blank control; ${ }^{* * *} \mathrm{P}<0.001 \mathrm{vs}$. blank control; ${ }^{* \#} \mathrm{P}<0.01 \mathrm{vs}$. EPCs/vector). e Significantly increase of thrombus recanalization and resolution was found in rats transplanted with EPCs transfected with miR-483-3p sponge compared to EPCs transfected miR-483-3p on Day 7. f The recanalization of thrombus was quantified with Image J software by the area ratio of contrast agent in vascular with thrombosis. Data are expressed as mean $\pm \mathrm{SEM}\left(\mathrm{n}=10\right.$, ${ }^{* *} \mathrm{P}<0.01 \mathrm{vs}$. blank control; ${ }^{* *} \mathrm{P}<0.001$ vs. blank control). Comparison among multiple groups was performed by one-way ANOVA followed by Least Significant Difference test

from DVT contributes to impaired EPCs function, which is likely due to decreased SRF.

Vein thrombi resolution is a complex and spontaneous process that requires the orchestration of different cells [25]. Three main steps include the infiltration of inflammatory cell into the thrombus, tissue remodeling and angiogenesis. The vascularization of the thrombus is an early and important event on the efficacy of thrombus resolution [25]. Growing evidences have suggested that bone marrow-derived EPCs are recruited into the thrombus and involved in the thrombus organization and resolution $[8,26]$. Several studies have reported the importance of EPCs in injured vessels repairmen and ischemic tissues revascularization [27]. We previously demonstrated that bone marrow-derived EPCs transplantation altered the vein microenvironment in a rat model of chronic vein thrombosis [28].

When DVT occurs, EPCs could home and migrate to the sites of neovascularization, increase new blood vessel formation in the injured site [29], and secrete a variety of vasoactive and angiogenic factors to improve angiogenesis thrombus resolution [25, 30]. In addition, EPCs have the potential to protect differentiated endothelial cells from apoptosis and to preserve their angiogenic capacity under conditions of oxidative stress [31]. The proposed mechanisms of EPCs in thrombus resolution are as follows. EPCs can home and integrate into the site of the injured vessels and thrombi and participate in orchestrating the angiogenesis process. EPCs residing in the thrombi can release a source of paracrine pro-angiogenic factors to induce vascularization. Moreover, EPCs produce proteinases to break down thrombi and secrete other factors to interact with platelets to prevent the apoptosis of mature endothelial cells and the formation of new thrombosis [32].

MiRNAs have been shown to play key roles in vascular development, homeostasis, function, disease and regeneration [33]. In particular, miRNAs have impact on angiogenesis and modulate the behavior of EPCs [15, 34, 35]. Therefore, we proposed that miRNA modified EPCs could improve the efficacy of EPCs in the thrombus resolution and recanalization. However, the potential of
EPCs-mediated cancer initiation should be paid attention [36].

MiR-483-3p is located within the insulin growth factor (IGF2) locus at chromosome 11p15.5 and implicated in various human cancers including colon, breast, liver cancers and squamous cell carcinomas [37, 38]. IGF2 is involved in angiogenesis through the regulation of the IGF/IGF2R system, and miR-483-3p was an intronic miRNA within IGF2. Until now, the exact role of miR483-3p in the function of EPCs has not been determined yet. In the present study, miR-483-5p emerges as a novel angio-miR that negatively regulates angiogenesis. By in vitro tube formation assay, we demonstrated that miR483-3p modulated angiogenic potential of EPCs. Moreover, we found that miR-483-3p regulated the migration and apoptosis of EPCs.

To elaborate putative mechanism by which miR-483-3p regulates EPCs function, we employed bioinformatics tool and molecular biology method to identify target gene. Our results suggested that SRF could be the potential target of miR-483-3p. SRF is involved in the regulation of multiple genes implicated in cell growth, proliferation, migration, apoptosis, cytoskeletal organization, energy metabolism and myogenesis [39, 40]. Moreover, SRF is important for the appropriate expression of structural proteins such as $\beta$-actin, VE-cadherin and several integrins in endothelial cells, and changed expression of SRF could lead to defective vascular morphogenesis [41]. In addition, SRF was reported to mediate FGF signaling in tracheal terminal branching and VEGF/FGF signaling in sprouting angiogenesis [42]. Indeed, previous study reported that miR-483-5p directly targeted SRF in human umbilical vein endothelial cells and inhibited angiogenesis in vitro [43]. Therefore, our present study extended previous findings on miR-483-SRF pathway from endothelial cells to EPCs.

There are some limitations in this study. Our results confirmed that SRF was a target of miR-483-3p and the suppression of SRF by miR-483-3p was involved in the effects of miR-483-3p on EPCs function. However, additional target genes are likely to participate in the anti-angiogenic effect of miR-483-3p, which remain to be investigated in 
the near future. Furthermore, the criteria of EPCs are still controversial. In this study, we used adherent PBMCs with the features of DiI-ac-LDL endocytosis and UEA-I expression binding, and the cells also showed the expression of CD34, CD133 and VEGFR-2. These EPCs have been shown to self-renew and form tube-like structures in vitro, and there might be several cell subpopulations in these EPCs.

\section{Conclusions}

In conclusion, this study shows that miR-483-3p is upregulated in EPCs from DVT patients and it impairs EPCs function via its target SRF. Furthermore, the application of EPCs transfected with miR-483-3p inhibitor into the vein thrombosis rat model improved the thrombus recanalization and resolution. These data suggest that miR483-3p might be employed as a therapeutic target in the treatment of thrombus in the clinical practice.

\section{Additional file}

Additional file 1: Figure S1. Identification of differentially expressed miRNAs in EPCs from healthy control and patients with DVT by microarray. The heat map diagram showed the results of the two-way hierarchical clustering of miRNAs and samples (Arraystar, human miRNA 18.0 chip). The color scale shown at the top illustrated the relative expression level of a miRNA in the certain slide: red color represented upregulated miRNAs while green color represented downregulated miRNAs.

\section{Abbreviations}

EPCs: endothelial progenitor cells; DVT: deep vein thrombosis; miRNA: microRNA; SRF: serum response factor; $3^{\prime}$-UTR: $3^{\prime}$-untranslated region; GFP: green fluorescent protein; IVC: inferior vena cava; DSA: digital subtract angiography.

\section{Authors' contributions}

$\mathrm{XL}$ and $\mathrm{CL}$ conceived the project. $\mathrm{LK}, \mathrm{NH}, \mathrm{XD}, \mathrm{WW}, \mathrm{HC}, \mathrm{WL}, \mathrm{SW}$ and $\mathrm{HZ}$ performed the patient collection, carried out the study protocol and data analysis. LK and NH wrote the paper. All authors read and approved the final manuscript.

\section{Author details}

${ }^{1}$ Department of Vascular Surgery, The Second Affiliated Hospital of Soochow University, No.1055, Sanxiang Rd, Suzhou 215000, Jiangsu, China. ${ }^{2}$ Department of General Surgery, The Fourth Affiliated Hospital of Anhui Medical University, Hefei 230022, China.

\section{Acknowledgements}

This work was supported by grants from the National Natural Science Foundation of China (No.81400345, No.30972941), Jiangsu Provincial Health Department's Medical Science Program (H201211), Graduate Research and Innovation Program in Colleges and Universities of Jiangsu Province (NO.1265).

\section{Competing interests}

The authors declare that they have no competing interests.

Received: 2 September 2015 Accepted: 6 January 2016

Published online: 22 January 2016

\section{References}

1. Saez-Gimenez B, Berastegui C, Loor K, Lopez-Meseguer M, Monforte V, Bravo C, Santamaria A, Roman A. Deep vein thrombosis and pulmonary embolism after solid organ transplantation: an unresolved problem. Transplant Rev (Orlando). 2014.

2. Piazza G, Goldhaber SZ. Acute pulmonary embolism: part l: epidemiology and diagnosis. Circulation. 2006;114:e28-32.

3. Weitz JI, Eikelboom JW, Samama MM. New antithrombotic drugs: antithrombotic therapy and prevention of thrombosis, 9th ed: American college of chest physicians evidence-based clinical practice guidelines. Chest. 2012;141:e120S-51S.

4. Isner JM, Kalka C, Kawamoto A, Asahara T. Bone marrow as a source of endothelial cells for natural and iatrogenic vascular repair. Ann N Y Acad Sci. 2001;953:75-84.

5. Rafii S, Lyden D. Therapeutic stem and progenitor cell transplantation for organ vascularization and regeneration. Nat Med. 2003;9:702-12.

6. Bozkirli ED, Keskek SO, Kozanoglu I, Yucel AE. High levels of endothelial progenitor cells can be associated with thrombosis in patients with Behcet's disease. Clin Exp Rheumatol. 2014;32:S49-53.

7. Meng QY, Li XQ, Yu XB, Lei FR, Jiang K, Li CY. Transplantation of VEGF165gene-transfected endothelial progenitor cells in the treatment of chronic venous thrombosis in rats. Chin Med J (Engl). 2010;123:471-7.

8. Modarai B, Burnand KG, Sawyer B, Smith A. Endothelial progenitor cells are recruited into resolving venous thrombi. Circulation. 2005;111:2645-53.

9. Bonauer A, Carmona G, Iwasaki M, Mione M, Koyanagi M, Fischer A, Burchfield J, Fox H, Doebele C, Ohtani K, et al. MicroRNA-92a controls angiogenesis and functional recovery of ischemic tissues in mice. Science. 2009;324:1710-3.

10. Parmacek MS. MicroRNA-modulated targeting of vascular smooth muscle cells. J Clin Invest. 2009;1 19:2526-8.

11. Plummer PN, Freeman R, Taft RJ, Vider J, Sax M, Umer BA, Gao D, Johns C, Mattick JS, Wilton SD, et al. MicroRNAs regulate tumor angiogenesis modulated by endothelial progenitor cells. Cancer Res. 2013;73:341-52.

12. Meng S, Cao J, Wang L, Zhou Q, Li Y, Shen C, Zhang X, Wang C. MicroRNA 107 partly inhibits endothelial progenitor cells differentiation via HIF1 beta. PLoS One. 2012;7:e40323.

13. Xu Q, Meng S, Liu B, Li MQ, Li Y, Fang L, Li YG. MicroRNA-130a regulates autophagy of endothelial progenitor cells through Runx3. Clin Exp Pharmacol Physiol. 2014:41:351-7.

14. Meng Q, Wang W, Yu X, Li W, Kong L, Qian A, Li C, Li X. Upregulation of MicroRNA-126 contributes to endothelial progenitor cell function in deep vein thrombosis via Its Target PIK3R2. J Cell Biochem. 2015;116(8):1613-23.

15. Wang W, Li C, Li W, Kong L, Qian A, Hu N, Meng Q, Li X. MiR-150 enhances the motility of EPCs in vitro and promotes EPCs homing and thrombus resolving in vivo. Thromb Res. 2014;133:590-8.

16. Hill JM, Zalos G, Halcox JP, Schenke WH, Waclawiw MA, Quyyumi AA, Finkel T. Circulating endothelial progenitor cells, vascular function, and cardiovascular risk. N Engl J Med. 2003;348:593-600.

17. Kalka C, Masuda H, Takahashi T, Kalka-Moll WM, Silver M, Kearney M, Li T, Isner JM, Asahara T. Transplantation of ex vivo expanded endothelial progenitor cells for therapeutic neovascularization. Proc Natl Acad Sci USA. 2000;97:3422-7.

18. Ma FX, Zhou B, Chen Z, Ren Q, Lu SH, Sawamura T, Han ZC. Oxidized low density lipoprotein impairs endothelial progenitor cells by regulation of endothelial nitric oxide synthase. J Lipid Res. 2006;47:1227-37.

19. Chang TC, Wentzel EA, Kent OA, Ramachandran K, Mullendore M, Lee KH, Feldmann G, Yamakuchi M, Ferlito M, Lowenstein CJ, et al. Transactivation of miR-34a by p53 broadly influences gene expression and promotes apoptosis. Mol Cell. 2007;26:745-52.

20. Chen T, Huang Z, Wang L, Wang Y, Wu F, Meng S, Wang C. MicroRNA$125 a-5 p$ partly regulates the inflammatory response, lipid uptake, and ORP9 expression in oxLDL-stimulated monocyte/macrophages. Cardiovasc Res. 2009:83:131-9.

21. Ebert MS, Neilson JR, Sharp PA. MicroRNA sponges: competitive inhibitors of small RNAs in mammalian cells. Nat Methods. 2007:4:721-6.

22. Chen L, Zhang K, Shi Z, Zhang A, Jia Z, Wang G, Pu P, Kang C, Han L. A lentivirus-mediated miR-23b sponge diminishes the malignant phenotype of glioma cells in vitro and in vivo. Oncol Rep. 2014;31:1573-80.

23. Li P, Sheng C, Huang L, Zhang H, Cheng Z, Zhu Q. MiR-183/-96/-182 cluster is up-regulated in most breast cancers and increases cell proliferation and migration. Breast Cancer Res. 2014;16:473. 
24. Lei FR, Li XQ, Liu H, Zhu RD, Meng QY, Rong JJ. Rapamycin and 3-methyladenine regulate apoptosis and autophagy in bone-derived endothelial progenitor cells. Chin Med J (Engl). 2012;125:4076-82.

25. Modarai B, Burnand KG, Humphries J, Waltham M, Smith A. The role of neovascularisation in the resolution of venous thrombus. Thromb Haemost. 2005;93:801-9.

26. Moldovan NI. Role of monocytes and macrophages in adult angiogenesis: a light at the tunnel's end. J Hematother Stem Cell Res. 2002;11:179-94

27. Santo SD, Tepper OM, von Ballmoos MW, Diehm N, Volzmann J, Baumgartner I, Kalka C. Cell-based therapy facilitates venous thrombus resolution. Thromb Haemost. 2009;101:460-4.

28. Li XQ, Meng QY, Wu HR. Effects of bone marrow-derived endothelial progenitor cell transplantation on vein microenvironment in a rat model of chronic thrombosis. Chin Med J (Engl). 2007;120:2245-9.

29. Zampetaki A, Kirton JP, Xu Q. Vascular repair by endothelial progenitor cells. Cardiovasc Res. 2008;78:413-21.

30. Asahara T, Isner JM. Endothelial progenitor cells for vascular regeneration. J Hematother Stem Cell Res. 2002;11:171-8.

31. Yang Z, von Ballmoos MW, Faessler D, Voelzmann J, Ortmann J, Diehm N, Kalka-Moll W, Baumgartner I, Di Santo S, Kalka C. Paracrine factors secreted by endothelial progenitor cells prevent oxidative stress-induced apoptosis of mature endothelial cells. Atherosclerosis. 2010;211:103-9.

32. Li WD, Li XQ. Endothelial progenitor cells accelerate the resolution of deep vein thrombosis. Vascul Pharmacol. 2015.

33. Kane NM, Thrasher AJ, Angelini GD, Emanueli C. Concise review: microRNAs as modulators of stem cells and angiogenesis. Stem Cells. 2014;32:1059-66.

34. Zuo K, Li M, Zhang X, Lu C, Wang S, Zhi K, He B. MiR-21 suppresses endothelial progenitor cell proliferation by activating the TGFbeta signaling pathway via downregulation of WWP1. Int J Clin Exp Pathol. 2015;8:414-22.
35. Zuo K, Zhi K, Zhang X, Lu C, Wang S, Li M, He B. A dysregulated MicroRNA26a/EphA2 axis impairs endothelial progenitor cell function via the p38 MAPKNEGF pathway. Cell Physiol Biochem. 2015;35:477-88.

36. Moschetta M, Mishima Y, Sahin I, Manier S, Glavey S, Vacca A, Roccaro AM, Ghobrial IM. Role of endothelial progenitor cells in cancer progression. Biochim Biophys Acta. 2014;1846:26-39.

37. Veronese A, Lupini L, Consiglio J, Visone R, Ferracin M, Fornari F, Zanesi N, Alder H, D'Elia G, Gramantieri L, et al. Oncogenic role of miR-483-3p at the IGF2/483 locus. Cancer Res. 2010;70:3140-9.

38. Bertero T, Bourget-Ponzio I, Puissant A, Loubat A, Mari B, Meneguzzi G, Auberger P, Barbry P, Ponzio G, Rezzonico R. Tumor suppressor function of miR-483-3p on squamous cell carcinomas due to its pro-apoptotic properties. Cell Cycle. 2013;12:2183-93.

39. Miano JM, Long X, Fujiwara K. Serum response factor: master regulator of the actin cytoskeleton and contractile apparatus. Am J Physiol Cell Physiol. 2007;292:C70-81.

40. Rodenberg JM, Hoggatt AM, Chen M, Touw K, Jones R, Herring BP. Regulation of serum response factor activity and smooth muscle cell apoptosis by chromodomain helicase DNA-binding protein 8. Am J Physiol Cell Physiol. 2010;299:C1058-67.

41. Franco CA, Mericskay M, Parlakian A, Gary-Bobo G, Gao-Li J, Paulin D, Gustafsson E, Li Z. Serum response factor is required for sprouting angiogenesis and vascular integrity. Dev Cell. 2008;15:448-61.

42. Franco CA, Li Z. SRF in angiogenesis: branching the vascular system. Cell Adh Migr. 2009;3:264-7.

43. Qiao Y, Ma N, Wang X, Hui Y, Li F, Xiang Y, Zhou J, Zou C, Jin J, Lv G, et al MiR-483-5p controls angiogenesis in vitro and targets serum response factor. FEBS Lett. 2011;585:3095-100

\section{Submit your next manuscript to BioMed Central and we will help you at every step:}

- We accept pre-submission inquiries

- Our selector tool helps you to find the most relevant journal

- We provide round the clock customer support

- Convenient online submission

- Thorough peer review

- Inclusion in PubMed and all major indexing services

- Maximum visibility for your research

Submit your manuscript at www.biomedcentral.com/submit

C BioMed Central 